\title{
Analysing the ways of participating in interview settings: young people's identity performances and social class in focus groups
}

\author{
Anu Katainen \& Riie Heikkilä
}

\begin{abstract}
Critical discussions on the focus group method have highlighted the importance of considering the forms of interaction generated in groups. In this empirical paper we argue that these forms of interaction are intimately linked to the ways participants interpret the study setting, and these interpretations are likely to differ significantly depending on participants' social backgrounds. In the light of our data consisting of 18 focus groups with 15-year-old school pupils from both affluent and deprived neighbourhoods of Helsinki discussing film clips about young people drinking alcohol, we ask what kinds of modes of participation are mobilised in focus group discussions in order to mark the social position of participants. We further analyse these modes in relation to situated identity performances, arguing that contextual factors of the study setting become especially important to consider when researching vulnerable groups and heterogeneous populations. The analysis yields three modes of participation: these are active/engaged, resistant/passive and dominant/transformative. We argue that these modes can be viewed as actively taken positions that reveal what kinds of identities and competences participants are able and willing to mobilise in the study setting, and that recognising these modes is important in all interview settings.
\end{abstract}

Keywords: Adolescents, focus groups, social class, qualitative methods

\section{Introduction}

Critical discussions on the focus group method have highlighted the importance of con-sidering not only content but also forms of talk and interaction generated in groups (Belzile and Öberg, 2012; Farnsworth and Boon, 2010; Johnson, 1996; Kitzinger, 1994; Wilkinson, 1998a). Yet, only a few attempts have been made to fully utilise focus groups by integrating interactive processes, group 
dynamics and presentation of self to the anal-ysis of what is discussed in groups (see Duggleby, 2005; Halkier, 2010; Hyde et al., 2005; Smithson, 2000). The importance of integrating group dynamics into the analysis of discussion contents is especially apparent in comparative research designs. Differing social and cultural contexts, situational determinants and the rapport created in groups ultimately determine how discussions evolve. The material generated through the focus group method thus depends on how groups work together and how participants experience the situation (Farnsworth and Boon, 2010; Hydén and Bülow, 2003).

The article draws on a previous study that examined meaning-making of alcohol use among adolescents in different social class milieus. The participants were shown film clips of young people drinking alcohol in order to stimulate focus group discussions of differing drinking practices. The aim of the original study was to compare the perceptions and ideas of the drinking scenes between groups representing varying class positions. However, a significant variation was found in the ways the participants reacted to the interview situation and interacted in the focus group setting, relating to the social class background of the participants. This made comparisons of attitudes and perceptions about alcohol challenging: while some groups discussed the social and cultural meanings of drinking based on what was depicted in the film clips, some groups did not engage with the task at hand. This finding demanded us to consider the limitations of the focus group method in studying heterogeneous populations. The differing reactions by participants required us to reflect on the underlying assumption regarding how participants are expected to perform themselves in a focus group situation. Thus, rather than concentrating on the outspoken attitudes towards different kinds of alcohol use, we ask what kinds of modes of participation are mobilised in the discussions in order to mark social positions.

The aim of this article is two-fold: first of all, our target is to show how differing par-ticipant reactions in focus groups can be seen as situated identity performances that should be paid more attention in all focus group designs and studies. As a logical second step, our aim is to identify the most salient modes of participation. Considerations of contextual determinants of research settings and identity performances produced in them (and because of them) are especially important in studies that involve minors or other vulnerable groups. It has been argued that the focus group method has the potential to democratise social scientific research as it permits participants' own voices to be heard in their own terms (Johnson, 1996; Smithson, 2000). Yet, focus group participation can cause stress and anxiety, as has been pointed out in ethical considerations of the method (Smith, 1995). 
Furthermore, less attention has been paid to the inequalities related to the capabilities and skills the focus group method actually requires from participants. The method relies on participants to disclose and share their beliefs and experiences while showing readiness to elaborate and justify their ideas if needed, as well as contributing to others' views in a reflexive manner (Wilkinson, 1998b). Participants are thus expected to be adept in group situations, to have good communication skills and to be able to take part in a reflexive discussion (Warr, 2005). When analysing classsensitive issues with a qualitative approach, it is important to note that social background is likely to affect the ways participants experience the research setting. Being in a face-to-face situation with a researcher or participating in a focus group requires skills of interaction and a reflexive orientation to the topic at hand. However, self-reflexivity is not something separate from social structures, but depends on resources and forms of capital that are bound to social position (Skeggs et al., 2008). We therefore argue that researchers should be more aware of their own underlying assumptions of the ways participants are expected to express themselves in focus group settings and recognise that participants may not share these assumptions.

In the context of this study, rather than showing how young people from differing backgrounds make sense of drinking situations, we will examine in what way the research setting enables differing articulations and performances of social identities (Allen, 2005). While there are many social identity categories that are potentially relevant to consider regarding the focus group interaction, we concentrate here on the implications of the performances related to social class. The concept of social class is understood, first, in terms of material dimensions of socio-economic position: we used area affluence and parental occupational status as bases of participant selection (see 'Study design'). Second, we see social class as socially constructed, referring to symbolically produced categories and identities that are lived in cultural practices (Bourdieu, 1984; Skeggs, 1997) and mobilised and performed within interaction situations (Hollingworth, 2015).

Our aim is not to claim that social class would be the most relevant category to our participants in relation their social identities. Rather, by examining modes of participation in relation to classed performances of the self, we want to critically highlight how researchers' understanding of the focus group setting can be radically different from those by participants. The participants utilise their cultural resources to produce performances of self within the conditions of a research setting (Skeggs et al., 2008), highlighting the importance of paying closer attention to the socially situated ways of participating in the focus groups. In this respect, the research setting as such, and the 
participants' ways of reacting and representing themselves as respectable in this particular setting, are closely scrutinised.

\section{Study design}

The material consist of 18 focus groups $(\mathrm{N}=86)$ involving 15 -year-old ninth grade school pupils in Helsinki, Finland. The participants were recruited from six schools in the Helsinki region. In order to reach pupils from varying social class backgrounds, we chose the schools from neighbourhoods that represented the most affluent and the most deprived areas in the Helsinki region. In order to consider the social class compositions of the groups, the participants were asked about their parents' occupational statuses with a questionnaire. The parents' occupations were used to categorise the participants roughly into working class (manual and service jobs), middle class (civil servants, different specialists) and upper class (management, medicine, finance, law) backgrounds. The participants were orally informed that taking part in the study was voluntary and they had the right to withdraw whenever they wished to do so. They were assured of confidentiality and informed that the recording was not to be heard by anyone other than the researchers. The data are carefully anonymised.

In each of the six schools, we appointed two classes to which we sent the invitations to participate via class teachers. The teacher then guided the interested pupils to join the group in a dedicated classroom. We expected to recruit six boys and girls from the same class to each group, creating 'natural groups' that would know each other since the beginning (cf. Wilkinson, 1998b). The groups varied between five and six pupils per group, but in one only three pupils showed up.

To systematise the data collection, the reception analytical group interview technique (RAGI) was used. In this method, carefully selected film clips are presented to all of the groups in a similar way (Sulkunen and Egerer, 2009). The idea was to give the inform-ants a chance to express their views as freely as possible by deliberately minimising the moderator's role. In the RAGI method, the moderator gives the instructions at the beginning of the discussion and shows a new clip whenever the discussion begins to wane. The method differs greatly from focus group formats in which the moderator's role is more active. This requires more self-direction from the participants as they need to determine themselves how to come to order to carry out the task. While participants are aware that there is a moderator present, the moderator does not support participants to take part in the discussion nor make sure that everyone can get their voice heard. 
The stimulus material consisted of short film clips that depicted young people drinking alcohol in various situations (Table 1). The RAGI method allows space for intra-group interaction and the discussion contents are largely determined by the group (see also Kitzinger, 1994; Warr, 2005). The choice of method was motivated by the goal to identify the ways young people understand differing drinking practices and how they negotiate with the varying situational determinants related to them (e.g., Demant and Törrönen, 2011). The chosen method thus required the participants to reflect on what they saw, which made the situation extra challenging. The participants had to rely on their reflexive skills and imagination by bringing out possible scenarios in group interaction. To ease the discussion and to enhance comparability, the participants were given a list of questions that guided them to consider what is happening in the clips, how realistic the episodes were from their point of view, what might have happened before and after those episodes and where the characters might be after ten years. The participants were instructed to discuss the clips freely and to answer the support questions.

Table 1. Film clips used as stimulus material.

\begin{tabular}{|l|l|l|}
\hline Film & Scene & Social situation \\
\hline Mean Creek (USA 2005) & $\begin{array}{l}\text { Male teenagers are drinking on a rowing boat. One of them offers the youngest one a } \\
\text { can of beer. }\end{array}$ & Small group \\
\hline Fucking Åmål (SWE 1998) & $\begin{array}{l}\text { In a home party a young girl disappointed by love affairs drinks from the bottle and } \\
\text { throws up. }\end{array}$ & Large group \\
\hline My Summer of Love (UK 2004) & A girl is taking a bath while drinking and smoking. & Alone \\
\hline Fjorton Suger (SWE 2004) & Two girls in a bedroom drink and then sing and dance on the bed. & Two girls \\
\hline Krampack (SPA 2002) & During dinner, an adult invites a boy to take a glass of wine. & Family \\
\hline Eurotrip (USA 2004) & A group of friends are drinking and dancing in a disco. & Small group \\
\hline
\end{tabular}

Instead of concentrating on the dynamics of entire interviews or single participants, the unit of analysis here was one individual turn (cf. Heikkilä and Kahma 2008), the idea being that an individual can dynamically alternate between different modes of participating during the interview. In the analysis of these modes, our starting point was first to explicate researcher's expectations on how focus groups should ideally perform to generate rich data for the purpose of analysis. We then reflect the actual participant reactions and conduct against these expectations. In the analysis, four dimensions of the ways the participants expressed themselves were considered: (1) activity in taking part in the discussion, (2) compliance to the given guidelines, (3) space given for other participants and (4) references to personal experiences. All these dimensions can be seen as relating to 
the ways in which the situation is experienced by participants and what kinds of social identities they feel relevant to express.

Activity refers here to engagement in the study setting and participation in the discussion by expressing one's ideas and views, which in general indicates confidence in the situation. Compliance with the given guidelines, on the other hand, can imply several things. It is an indication of the willingness to act within a certain framework or task, but it also requires that explicit and implicit situational norms are considered fair and accept-able. Space given for others in the discussion relates to the establishment of a common communicative ground (Hydén and Bülow, 2003), as well as letting everyone in the situation become heard and recognised as members of the group. This kind of action in the focus group setting can be viewed as an indication of social skills but at the same time it relates to the hierarchies formed within a group. Dominant participants are likely to be those who regulate, either intentionally or unintentionally, the flow of discussion and other participants' possibilities to take part. Domination in the group and the dynamics that follows therefore determine what kinds of modes and self-expressions become possible and are encouraged (Kidd and Parshall, 2000). Also, the rapport created in group shows in the ways participants are able to express dissenting views.

Finally, referring to personal experiences allows participants to mobilise cultural competences that can be highly relevant for their self-narrative. This implies a confidence in the situation and a relatively strong position in the group, as bringing out personal notions can contain a risk of selfexposure and becoming judged by others. Also, referring to one's own experiences was not explicitly encouraged in the instructions of this study, although the participants were free to talk about whatever came to mind. Using their own experiences as a ground for interpretation thus indicates the participants' confidence in defining appropriate ways of expressing oneself.

Based on these analytical dimensions, altogether three main types of modes were recognised in this study: active/engaged, resistant/passive and dominant/transformative. Here, modes of participating are not seen as stable behavioural patterns, but as presentations of self in the dynamic and fluctuating interview context: in focus groups, like in any social interaction, people are constantly constructing themselves by negotiating and per-forming their self-narratives (Halkier, 2010). Modes of participation are formed as an interplay of learned behaviour, situational and interactional rules and an individual's evaluation of the situation and his/her motivations and intentions in that situation. Furthermore, modes of participation are not necessarily constant over the course of the 
situation, in this case the focus group interview. Participants may adopt and express differing modes depending on how the circumstances evolve.

Modes of participation can be further analysed as situated identity performances, in which self is presented in front of observers, in this case the moderator and other participants (see also Allen, 2005). The idea of performativity derives from the work of Judith Butler and has been powerfully influential especially in gender studies, but it has also been applied in youth studies involving class, race and ethnicity (Francis et al., 2010; Hollingworth, 2015; Youdell, 2003). Butler's (1993) idea of performativity supposes that identities are produced and maintained by performative actions, not the other way around. Regarding youth and social class, this framework helps to understand young people's agencies as bounded and constituted by social circumstances, contexts and barriers, and identifies ways in which young people perceive these circumstances and act within them (Evans, 2002). The idea of performativity of class-related identities brings forward the notion of how young people themselves construct and maintain identity categories within their local contexts (David et al., 2006). In this study, identity categories, such as class, were considered heterogeneous positions constructed and performed over the course of the interview situation (Törrönen, 2014). The focus group setting therefore becomes a site of constant negotiation of meanings and identities (Crossley, 2002). In this sense, the research setting can be viewed as an experiment in how participants from heterogeneous backgrounds deal with the situation and what kinds of expectations they have regarding the presentation of self in that particular situation.

\section{Analysis: participant roles as situated identity performances}

\section{Activelengaged}

Participation in a focus group discussion presupposes that the participant accepts the general principles and implicit rules of the setting, is willing to adopt the goals imposed by the researcher and actively engages in the setting to reach those goals. These skills can be understood at least partly as a result of the prevalence of research interviews and people getting used to them, coined as the emergence of an interview society (Atkinson and Silverman, 1997). Typically, focus group participants comply with these rules and assume the mode of an 'engaged participant'. Although the purpose of these interviews was to enable a free flow of discussion among participants and they were also encouraged to express their ideas freely, the presence of support questions and the instruction to address them implied that the discussion was expected to relate to the events in the 
clips. The identity performances complying with active modes and following given instructions is called here the active/engaged mode. This mode emerged in the groups where participants were mutually given space to express their views. The groups followed the given instructions by talking freely about differing topics and by addressing the support questions. The next excerpt concerning the clip in which the character, a young girl, is lying in the bathtub, drinking beer and smoking a cigarette, exemplifies well this kind of 'ideal' of group dynamics and discussion:

B3: I suggest that one possibility to interpret the situation is that she's a bit depressed, I mean the girl, and she's trying, I mean, she is using substances in order to feel better, so that . . . well she looked like she wasn't in the best shape.

G6: And before that something bad or sad had happened to her.

B3: Yeah.

B1: Mmm.

G6: I suppose after this ... I don't know. She's there alone or then she's got some friends there, hard to tell. It may be that she stops drinking before it's too late, or maybe not. She could end up being really drunk and if we, for example, think that some guy had just dumped her, she'll probably call him and ask him to come back. I mean if she's too drunk or something.

B1: Or option number four: she passes out and drowns.

G6: Yeah. I think something like that could happen in real life.

B1: It could happen but I don't understand what the bathtub has got to do with ...

B3: I was just thinking about the same thing.

B1: The bathtub isn't that. . But on the other hand, if she's drinking for her depression, she may, without actually consciously wanting it, try to commit a suicide or something like that.

B3: . . basically it's just the same when you drink if you are depressed. Maybe the bathtub is a bit of a strange place, but why not?

B5: It's risky if she passes out.

G6: Yeah.

B3: But she wasn't drinking too much really or at least there weren't many bottles there. I don't know if it was made to look like that on purpose.

B1: Yeah, and actually you couldn't tell if she was just relaxed, or if she was actually slurring a bit.

B3: Exactly, because it's possible that she's only relaxing there, so that it's a bit difficult to interpret.

(Group 2, six participants, affluent neighbourhood, middle to upper class parents.) 
In this excerpt, the participants give several alternative interpretations for what might be happening. Boy 3 opens the discussion by explicitly stating that his interpretation is just one possibility; by doing this, he keeps the discussion open for other suggestions. Girl 6 agrees by continuing with the next support question, 'What might have happened before?' and after Boy 3 and Boy 1 agree with her, she also expresses her suggestion for what might happen later. The participants make several suggestions: after Boy 1 brings up the possibility of a suicide, Boy 3 points out that the girl did not seem to be drinking heavily. Boy 1 agrees and gives an alternative explanation. The group does not settle with one interpretation but shows openness for other views, which becomes especially salient in the Boy 3's turns as he ends up in a completely different interpretation compared to the view he first expressed.

Adopting active and engaged mode in focus group settings can be seen as an identity performance built on the competence of handling the situation and its implicit rules: to do what is expected and to do it well. The focus group setting, in this sense, becomes a site of showing one's interactive and reflexive skills. In active/engaged mode, the participant's experience of respectability coincides with the expectations of the setting and they are willing to adopt a mode that can be seen as representing the middle or upper middle class ideal of how to express oneself in group interaction (DiMaggio, 2012). So far we have examined general activity, compliance and space given for others, but in relation classed performances, references to personal experiences turned out to be most revealing in terms of performing middle-class identities. In the next excerpt, the participants dis-cuss about a clip where a boy is poured a glass of wine during dinner:

G3: [It seems] like they are in Spain, so don't you think it's quite normal there?

G1: Yeah.

B1: Yeah.

G1: I was visiting my grandmother on Independence Day, so I actually had a glass of white wine, because in my family it has always been so that ... It's like wine is a drink for civilised people, so in that sense I'm used to it.

B4: Yeah, and then there are those adults around, so it should be fine.

(Group 1, six participants, affluent neighbourhood, working class to upper class parents)

Here, Girl 1 associates the events of the clip with her own experiences with her family and refers to their habit of having a glass of wine in special events as civilised behaviour. The girl 1 thus 
expresses her symbolic capital through an ability to evaluate the appropriateness of drinking styles by referring to her familiarity with drinking culture with all its nuances. The situation allows the participant to ascribe cultural capital to her family and their practices in a way that is accepted by others in the group as boy 4 affirms the notion and continues by referring to the safety of the described situation. Own experiences and previous knowledge were also used as a basis for judgements of taste, reflecting well Bourdieu's (1984) idea about embodied cultural capital:

B1: Yeah, from my point of view, that could, in a sense, happen, I mean, at a home party and people are drinking and so on, but I think they looked a bit older than we are. In addition, I think that Finnish people use a glass when they drink. At least based on my experience. It looked a bit stupid when everyone had such big bottles.

B3: They were kind of at a Swedish party I guess.

B1: Yeah. (Laughing)

(Group 1, six participants, affluent neighbourhood, working class to upper class parents)

In this excerpt, Boy 1 indicates disapproval for drinking straight from the bottle by refer-ring to his own experience. Boy 3 then jokingly indicates that drinking wine from the bottle is something typical of Swedes. The film clip excerpt concerns a Swedish film, but boy 3's reference to the Swedish party is likely to indicate something else as the statement is followed by laughter. In a prevalent cultural schema in Finland, Swedes are considered culturally superior, deriving from the history of Finland as part of the Swedish kingdom. Here the judgement of taste concerns Swedes as having less cultural capital regarding 'civilised' drinking habits. These kinds of statements can be seen as expressions of competence involving an assessment of a culturally appropriate way of using alcohol, exemplifying a version of middle-class cultural goodwill (cf. Bourdieu, 1984).The focus group setting in this study was especially ideal for performing middle-class identities as it provided a situation to express reflexive abilities and judgements of taste in terms of drinking styles. This is not to say that all participants adopting active/engaged modes would come solely from middle or upper class backgrounds. Rather, the situation and group dynamic called for or enabled these kinds of performances.

\section{Passive/resistant}


The participants for each group were recruited from the same school class. The original purpose was to ease the discussion by ensuring that everyone in the group knew each other (Warr, 2005; Wilkinson, 1998b). However, this meant that the norms and hierarchies that already existed in the group were likely to affect the dynamics of discussion (Kitzinger and Barbour, 1999). The preexisting hierarchies or negative relationships between participants may show, for example, through some participants' unwillingness to engage in the conversation. Quietness in the focus group setting may imply that the participants do not know what is expected from them or be an indication of outright resistance towards the situation (for a thorough discussion on 'problematic silences' in focus group contexts, see Hollander, 2004). In this study with teenagers, passivity and resistance came up in several ways. First, there were a few participants who did not speak at all - possibly a reaction signalling shyness or awkwardness towards the topics and the research setting. Second, and contrary to the active/engaged modes, passive mode refers to a minimal participation in the conversation. In the passive mode, the responses were short and the clips were reflected upon only superficially.

In passive mode, the support questions were necessary to get the group in action. When the support question was posed by a participant who had taken - or was given - the dominant position, the first response was typically accepted as a view of the whole group with nods or affirmative sounds (Heikkilä and Kahma, 2008). Alternative views were rarely expressed and the group settled with the interpretation that was first given. In the next excerpt, the group discusses the boys on the rowing boat:

G1: Okay, so should we just start to discuss this?

Moderator: Yeah, just go ahead.

B1: Yeah.

G1: What happened in the clip? (Laughing)

G2: Some older guy gives the younger one alcohol.

G1: How sad.

G2: And ...

G1: He wasn't so happy about it, it seemed.[...]

G2: What could have happened before?

G1: Well, maybe, they were just sitting on the boat.G2: Full beer cans in their backpack.

G1: Oh, my god.

G2: I mean really. What happened after this? 
G1: Well, the boy probably drinks the beer with that expression on his face because his big brother drank too.

G2: That's right. Then they are pissed.

$\mathrm{G} 2$ : What kind of people are they in ten years?

B3: Normal.

G1: Yeah.

B4: Yeah.

G2: Yeah like ...

G1: Yeah, normal.

G2: Could this happen in real life?

B3: Yeah.

B4: Yeah.

G1: Yeah

G2: Yeah.

(Group 15, five participants, affluent neighbourhood, working class to upper class parents)

In this excerpt, Girl 1 first takes the leading role and opens the discussion by directing a question to the moderator and then posing the first support question. Later, Girl 2 takes the role of asking the questions and Girl 1 and Boy 3 give the first responses. Other participants do not challenge their views or offer any alternative interpretations. The discussion seems like a compulsory school task that they are only interested in completing. In the passive mode, own experiences were not employed and the discussions concerned mostly the immediate aspects in the scenes. While in the active and engaged modes imagination was used when figuring out the meaning of the scenes, in the passive ones only very apparent events in the clips were noticed and not much effort was put into considering, for example, the qualities of the characters or the possible consequences of the events. This kind of discussion provides little material for qualitative analyses, but it is illustrative of the varying ways in which focus group participants may position them-selves in the situation.

In the passive mode participants refused to fully involve themselves in the situation. However, passivity in the situation can be seen as an identity performance, and thus meaningful reaction in the situations, if it is understood as a form of resistance: in the passive mode the participant is able to take distance from the situation and by doing this to shows to others that he or she is above it, as full engagement could be interpreted as compliance in a negative sense. In this study, the passive participant modes were not associated with any particular class position. 


\section{Dominant/transformative}

Active/engaged and passive/resistant modes of participation were similar in the sense that in these modes the discussion concerned the events of the clips. The third mode of participation recognised in this study, dominant/transformative, was characterised by the partial or total abandonment of the given instructions. While 'problematic silences' dominated the passive/resistant discourse, the dominant/transformative mode could be interpreted as a variant of 'problematic speech' (Hollander, 2004) in which the group interaction is biased by peer pressure, for instance through exaggeration or attempts to show strength and dominance vis-à-vis others. Those demonstrating dominant/transformative modes were without exception boys from working-class backgrounds. In the context of this mode, the participants were dominant in the ways they took leading roles by defining the appropriate ways of interacting in the situation, on one hand, or discussing alcohol-related matters, on the other. The dominant/transformative turns typically concerned the participants' own drinking experiences instead of the events in the clips. In the next excerpt, the participants discuss the boys on a rowing boat:

B5: Yeah. Not good. Could this happen in real life?

B2: Yeah...

B1: I guess.

B4: Yeah.

B2: Absolutely.

B5: On the boat in the middle of fucking nowhere.

B1: In Herttoniemi [city district in Helsinki].

B5: (Laughs) In Herttoniemi, yeah.

B1: That was where we once stole a car.

B5: That was a good boat.

B1: How would you know about that? You weren't there.

B5: I saw that. Just didn't feel like watching when you tried to break that lock.

B1: It was more fun on the second time.

B5: Yeah, rowing on the piece of wood.

B1: It was fun.B5: It certainly must have been.

B1: (. . .) but it was destroyed.

B5: You should have killed them. 
B1: But we couldn't catch them because they had gone too far.

(Group 9, five participants, deprived neighbourhood, working class parents)

First, the participants begin to casually discuss the clip, indicating passive/resistant mode with short, uninterested responses. Boy 5 refers to the support question by asking the others if the events could take place in real life. The clip seems to remind Boy 1 about a real-life event and he mentions the name of a city district. After Boy 5 remembers and affirms this memory, Boy 1 relates an incident of stealing a car. What is also noteworthy is that while this controversial incident is revealed, the discussion becomes rather incomprehensible. They do not explicitly reveal what had happened. Instead, the incident is referred to through inside jokes. Even though the boys in this excerpt do not follow the expectation that the discussion should focus on the clips, they are not passive or resistant in a sense that they would refuse to participate. The discussion is triggered by the events in the clip and the matters they bring out are not coincidental: their own experiences are juxtaposed with the events in the clip.

References to personal stories can also be understood as a way of strengthening the group cohesion, but simultaneously they can be seen as expressions of one's position in the group, and, in relation to the events in the clips. The domination can be seen as appearing in two ways: in the dominant mode the participants, first, took their space in the situation and led the discussion. Second, in the dominant mode the course of discussion is turned to highlight one's personal competence, but differently from active/engaged mode: own experiences are not used as a ground for judgements of taste. Instead, the study setting is transformed into an opportunity to reveal personal experiences relevant in the context:

B2: That was too short.

Moderator: You can begin by discussing what happened in the clip.

B1: Nothing.

B4: Well, nothing.

B3: They were boating.

B5: They were boating and having alcoholic drinks. A really bad combination.

B4: Yeah.

B3: Isn't that the purpose of going on the ferry (laughs)? (laughter)

B2: (laughs) Yeah, on the ferry but that wasn't a ferry.

B5: You mean a Swedish ferry. 
G6: Well, if you row by yourself it may be quite . .

B5: ... yeah, it's much funnier in that way.

B4: Yeah. Then it's really fun.[...]

Moderator: Could this happen in real life?

B5: Yeah, it could.

B3: Yeah.

G6: Easily.

B4: I think that's pure imagination.

B1: Let's not go into details now.

Moderator: I think we could go into details. (laughter)

B1: Let's not talk about Mike's ... (laughter)

B5: They were rowing. I also row sometimes.

G6: Yeah.

B5: Mm.

G6: And maybe ...

B5: Well, it's quite, no ...

B2: Oh, you mean in your bathroom?

B1: (laughs)

(Group 10, six participants, deprived neighbourhood, working class parents)

Here, the discussion did not begin spontaneously so the moderator instructed the group to talk about what had occurred in the clip. Boy 1 states that there was nothing happening and Boy 4 agrees. After this, Boy 5 gives a risk evaluation of the situation by stating that drinking and boating is a bad combination. Boy 3 associates the events with a ferry trip 1 but it remains unclear whether any of the participants have actually experienced a 'booze cruise'. However, the reference to rowing seems to trigger some mutual memories that are presumably linked to Boy 5. As in the previous excerpt, the incident is not revealed in full as it is expected that all the relevant persons in the group know to which event they are referring. Partial referencing to mutual experiences can thus be seen as a practice of boundary-making within the group.

In the dominant/transformative mode, the participants' responses were often only loosely related to the events in the clips. They did not have a lot to say, and there was only a minimal effort to reflect on the characters' drinking. However, the discourse differs from the passive one as in dominant/transformative mode the interaction is active even though it proceeds differently from 
what was expected. This kind of participation may be, first, due to the demands of the research setting: the participants might not have enough resources to discuss in a reflective manner in a formal group situation. This interpretation is supported by the fact that there were more discussion on the clip if the participants had actually seen the film. In this case, the support questions were answered according to what had really happened in the film. Second, it is possible that the participants did not want to comply with the implicit rules of the setting. However, unlike the passive modes, dominant/transformative modes included bragging about the participants' drinking experiences, as in the excerpts above: the participants eagerly position themselves in situations of drinking and other forbidden activities. The focus group discussion offered the participants operating through the dominant/transformative mode an opportunity to express and even show off with this experience, but in a way, that also boosted their position within the group.

As an identity performance, dominant/transformative mode can be seen as an expression of an ability to resist the norms of the mainstream school culture and to define one's own situational rules. In this regard, these kinds of identities expressed resemble in many ways the counter-school culture famously described by Paul Willis, reminding of the fact that the opposition to the authority and conformism offered by school is an important building block of the identity of working-class boys (1977; see also Martino, 1999). They embodied the figure of a 'delinquent' who distances himself from the middle-class school culture and whose respectability derives mainly from the roles that take place outside the formal structures of school. The focus group setting in this study enabled expressions of those roles within the school context. In these kinds of identity performance, everyday resistance and rule-breaking become ways of expressing one's capabilities (Aaltonen, 2013). However, they are in sharp contrast with what is valued in school and what are seen as indicators of successful pupils. Yet, the point of view of identity performances suggests that dominant/transformative modes in formal research settings should not be seen simply as noncompetent or disobedient and the active/engaged as compliant. From the performative point of view, both modes imply their own kinds of ideals of respectability, given the structural context of the study setting.

\section{Discussion and conclusions}

The empirical examples presented in this article show how focus group settings with adolescents become sites of differing expressions and ideas of agency and how classed positions are performed in reactions to the research setting. In this study, we recognised three main kinds of modes of 
participation: active/engaged, resistant/passive and finally dominant/transformative. While the data used here touched upon the social meaning-making of alcohol through the voices of Finnish underage adolescents, we argue that these same modes could probably be identified in virtually any set of focus group data. In the same vein, we believe that pinpointing and assessing them might be at least as relevant for the findings as the subject matter of the interviews. The approach of analysing modes of participation can be also used to include the process of dynamic interaction and participant reactions to the analysis of discussion contents. The modes of participation recognised in this study and the dimensions of identity performances are summarised in Table 2 .

Modes of participation can be viewed as actively taken positions that reveal some-thing significant about how the participants interpret the setting, how they perceive their role, what kinds of expressions of identity they see possible and worth emphasising and what kinds of competences they are able and willing to mobilise in the formal interview situation (cf. Silva and Wright, 2005). They reflect collective understandings of what is considered respectable and what kinds of skills and forms of cultural capital are valued (Skeggs, 1997). The young participants of this study actively produced performances of themselves by signifying and valuing drinking and by their behaviour in the research setting. These performances can be seen as both reflections and reproductions of the sense of their position in the social space (Kolind, 2011).

The analysis of modes of participation in a study that involved participants from varying social class positions is an important reminder of the multitude of personal, situational and cultural factors affecting the ways in which focus group participants react to the setting and perform themselves in the situation. The focus group interview always legitimises some discourses as it efficiently silences others (Silva and Wright, 2005: 250). While the objective of the focus group method is usually to enable interaction between individuals and in this sense to provide a natural setting for joint production of accounts on a given topic, interaction is never neutral but always involves positions of power (Allen, 2005). What is more, when studying young people, the research situation inherently involves a hierarchy between an adult and a child. Similarly, experienced social distance between participants and/or between the participant and the moderator is likely to further induce articulations of these power relations. Moreover, the 'micro-dynamics of power' (Ayrton, 2018) in focus groups reveal not only hierarchies and positions relevant in participants' local contexts but also in the wider society. 
The focus group is a potentially demanding method for different kinds of vulnerable groups, among them young participants such as children and adolescents. Previous literature has emphasised the strengths of the method to reach the views of diverse and even marginal groups (Halcomb et al., 2007). However, the study at hand points at the limitations of the focus group method: depending on their backgrounds and age, people can be unequally equipped to participate. Our study indicates that young people from different social milieus can have varying skills and expectations for participating in such situations, an issue that should be further discussed in qualitative studies applying inter-view methods, especially focus groups. The reactions to the study setting are likely to differ, as well the situated interpretations of the appropriate ways of expressing oneself. In this sense, the focus group setting can be understood as an experiment: it is an artificial setting in which participants feel that they are expected to behave in a certain way. Depending on the interpretations of the situation, reactions are likely to differ consider-ably. It is our duty as researchers to make interaction in focus groups as easy as possible in different kinds of heterogeneous populations in order to truly keep on being able to access and offer a voice to all kinds of groups and people. This requires that our methods are adapted to the requirements of our study populations.

Table 2.Modes of participation and dimensions of identity performances.

\begin{tabular}{|l|l|l|l|l|}
\hline $\begin{array}{l}\text { Dimensions of } \\
\text { identity } \\
\text { performances }\end{array}$ & \multicolumn{2}{|c|}{ What is observed? } & \multicolumn{1}{|c|}{ Active/engaged } & \multicolumn{2}{|c|}{ Passive/resistant } \\
\cline { 3 - 5 } General activity & $\begin{array}{l}\text { Do the participants take } \\
\text { part in the discussion? } \\
\text { How engaged they are in } \\
\text { the situation? }\end{array}$ & $\begin{array}{l}\text { Confidence in the situation, } \\
\text { engagement in the } \\
\text { establishment of common } \\
\text { ground }\end{array}$ & $\begin{array}{l}\text { Withdrawal from the } \\
\text { discussion, minimum activity } \\
\text { in the discussion }\end{array}$ & $\begin{array}{l}\text { Confidence in the situation, } \\
\text { taking a dominant position in } \\
\text { the group }\end{array}$ \\
\hline Compliance & $\begin{array}{l}\text { Do the participants } \\
\text { follow given instructions } \\
\text { and implicit rules of the } \\
\text { study setting? }\end{array}$ & $\begin{array}{l}\text { Compliance with the explicit } \\
\text { and implicit rules of the } \\
\text { situation }\end{array}$ & $\begin{array}{l}\text { Compliance with the explicit } \\
\text { rules of the situation }\end{array}$ & $\begin{array}{l}\text { Negligence of explicit rules } \\
\text { of the situation, redefining the } \\
\text { situation and its purpose }\end{array}$ \\
\hline Giving space & $\begin{array}{l}\text { Do the participants give } \\
\text { others the possibility to } \\
\text { express themselves? }\end{array}$ & $\begin{array}{l}\text { Giving space for others but } \\
\text { also confidence in taking a } \\
\text { lead if necessary }\end{array}$ & $\begin{array}{l}\text { The discussion space is left } \\
\text { for others }\end{array}$ & $\begin{array}{l}\text { The space is taken for oneself } \\
\text { or a small group of dominant } \\
\text { participants }\end{array}$ \\
\hline $\begin{array}{l}\text { Referencing to } \\
\text { own experience }\end{array}$ & $\begin{array}{l}\text { How do the participants } \\
\text { make use of and express } \\
\text { their own experiences? }\end{array}$ & $\begin{array}{l}\text { Backing up one's views by } \\
\text { personal experiences, using } \\
\text { them as measurements for } \\
\text { appropriate ways of conduct }\end{array}$ & $\begin{array}{l}\text { Own experiences are not } \\
\text { expressed }\end{array}$ & $\begin{array}{l}\text { Discussion stimuli are used as } \\
\text { reference points to bring out } \\
\text { one's personal competences }\end{array}$ \\
\hline
\end{tabular}

Throughout different research contexts, focus groups are often used together with other methods in order to triangulate on the research question (cf. Skeggs et al., 2008). Our paper showed once again that the focus group method is also fruitful used on its own: it brings the group dynamics and shifting participant modes into the fore in a way that is difficult to achieve through virtually any other method, which contributes especially to the understanding the dynamics of vulnerable groups. Further research might explore, for instance, how different modes of participation are mobilised 
across different research contexts and pay closer attention to what kinds of capitals and competences are associated to which modes.

This work was supported by the Academy of Finland, grant number 258195.

ORCID iDAnu Katainen https://orcid.org/0000-0002-7624-2677

Note1. 'Ferry' refers here to the cruises between Helsinki and Stockholm, popularly considered 'booze cruises' because alcohol is cheaper in the duty-free shops and the restaurants and bars aboard ship.

\section{References}

Aaltonen S (2013) 'Trying to push things through': forms and bounds of agency in transitions of school-age young people. Journal of Youth Studies 16(3): 375-390.

Allen L (2005) Managing masculinity: young men's identity work in focus groups. Qualitative Research 5(1): 35-57.

Atkinson P and Silverman D (1997) Kundera's Immortality: the interview society and the invention of the self. Qualitative Inquiry 3(3): 304-325.

Ayrton R (2018) The micro-dynamics of power and performance in focus groups: an example from discussions on national identity with the South Sudanese diaspora in the UK. Qualitative Research. Epub ahead of print 6 June 2018. DOI: 10.1177/1468794118757102

Belzile JA and Öberg G (2012) Where to begin? Grappling with how to use participant interaction in focus group design. Qualitative Research 12(4): 459-472.

Bourdieu P (1984) Distinction. A Social Critique of the Judgement of Taste. London: Routledge \& Kegan Paul.

Butler J (1993) Bodies That Matter: On the Discursive Limits of 'Sex'. New York: Routledge. Crossley ML (2002) 'Could you please pass one of those leaflets along?': exploring health, morality and resistance through focus groups. Social Science \& Medicine 55(8): 1471-1483.

David M, Coffey A, Connolly P, et al. (2006) Troubling identities: reflections on Judith Butler's philosophy for the sociology of education. British Journal of Sociology of Education 27(4): 421424.

Demant J and Törrönen J (2011) Changing drinking styles in Denmark and Finland. Fragmentation of male and female drinking among young adults. Substance Use \& Misuse 46(10): 1244-1255. 
DiMaggio P (2012) Sociological perspectives on the face-to-face enactment of class distinction. In: Fiske S and Markus H (eds) Facing Social Class: How Societal Rank Influences Interaction. New York: Russel Sage Foundation, 15-38.

Duggleby W (2005) What about focus group interaction data? Qualitative Health Research 15(6): 832-840.

Evans K (2002) Taking control of their lives? Agency in young adult transitions in England and new Germany. Journal of Youth Studies 5(3): 245-269.

Farnsworth J and Boon B (2010) Analysing group dynamics within the focus group. Qualitative Research 10(5): 605-624.

Francis B, Skelton C and Read B (2010) The simultaneous production of educational achievement and popularity: how do some pupils accomplish it? British Educational Research Journal36(2): $317-340$.

Halkier B (2010) Focus groups as social enactments: integrating interaction and content in the analysis of focus group data. Qualitative Research 10(1): 71-89.

Halcomb EJ, Gholizadeh L, DiGiacomo M, et al. (2007) Literature review: considerations in undertaking focus group research with culturally and linguistically diverse groups. Journal of Clinical Nursing 16(6): 1000-1011.

Heikkilä R and Kahma N (2008) Defining legitimate taste in Finland: Does mother tongue matter? Research on Finnish Society 1(1): 31-44.

Hollander JA (2004) The social context of focus groups. Journal of Contemporary Ethnography 33(5): 602-637.

Hollingworth S (2015) Performances of social class, race and gender through youth subculture: putting structure back into youth subcultural studies. Journal of Youth Studies 18(10): 1237-1256. Hyde A, Howlett E, Brady D, et al. (2005) The focus group method: insights from focus group interviews on sexual health with adolescents. Social Science \& Medicine 61(12): 2588-2599. Hydén LC and Bülow PH (2003) Who's talking: drawing conclusions from focus groups - some methodological considerations. International Journal of Social Research Methodology 6(4): 305321.

Johnson A (1996) "It's good to talk": The focus group and the sociological imagination. The Sociological Review 44(3): 517-538.

Kidd PS and Parshall MB (2000) Getting the focus and the group: enhancing analytical rigor in focus group research. Qualitative Health Research 10(3): 293-308.

Kitzinger J (1994) The methodology of focus groups: the importance of interaction between research participants. Sociology of Health and Illness 16(1): 103-121. 
Kitzinger J and Barbour RS (1999) Introduction: the challenge and promise of focus groups. In: Barbour R and Kitzinger J (eds) Developing Focus Group Research: Politics, Theory and Practice. London: Sage, 1-20.

Kolind T (2011) Young people, drinking and social class. Mainstream and counterculture in the everyday practice of Danish adolescents. Journal of Youth Studies 14(3): 295-314.

Martino W (1999) 'Cool Boys', 'Party Animals', ‘Squids' and 'Poofters': interrogating the dynamics and politics of adolescent masculinities in school. British Journal of Sociology of Education 20(2): 239-263.

Silva EB and Wright D (2005) The judgement of taste and social position in focus group research. Sociologia e Ricerca Sociale 26(76-77): 241-253.

Skeggs B (1997) Formations of Class and Gender. London: Sage.Skeggs B, Thumin S and Wood H (2008) 'Oh goodness, I am watching reality TV'. How methods make class in audience research. European Journal of Cultural Studies 11(1): 5-24.

Smith MW (1995) Ethics in focus groups: a few concerns. Qualitative Health Research 5(4): 478486.

Smithson J (2000) Using and analysing focus groups: limitations and possibilities. International Journal of Social Research Methodology 3(2): 103-119.

Sulkunen P and Egerer M (2009) Reception analytical group interview. A short introduction and manual. Report for the Department of Sociology. Research Reports no 260. Helsinki: University of Helsinki.

Törrönen J (2014) Situational, cultural and societal identities: analysing subject positions as classifications, participant roles, viewpoints and interactive positions. Journal for the Theory of Social Behaviour 44(1): 80-98.

Warr JD (2005) "It was fun . . . but we don't usually talk about these things": analyzing sociable interaction in focus groups. Qualitative Inquiry 11(2): 200-225.

Wilkinson S (1998a) Focus groups in health research: exploring the meanings of health and illness. Journal of Health Psychology 3(3): 329-348.

Wilkinson S (1998b) Focus group methodology: a review. International Journal of Social Research Methodology 3(1): 181-203.

Willis P (1977) Learning to Labour: Why Working Class Kids Get Working Class Jobs. Farnborough: Saxon House.

Youdell D (2003) Identity traps or how black students fail: the interactions between biographical, sub-cultural, and learner identities. British Journal of Sociology of Education 4(1): 3-20. 


\section{Author Biographies}

Anu Katainen is a senior lecturer in social and public policy and has a title of docent in sociology at the University of Helsinki, Finland. Her research on health inequalities and substance use draws on various qualitative data, such as individual interviews, focus groups and online discussions. She has specialised in comparative qualitative research designs, most recently as a PI in projects on social class differences in youth drinking cultures and alcohol marketing on social media.

Riie Heikkilä is a post-doctoral researcher in sociology at the University of Tampere, Finland. Her research focuses on cultural capital, cultural consumption and especially the non-consumers of culture, social stratification, and comparative sociology in general. She co-edited Enter Culture, Exit Arts? The Transformation of Cultural Hierarchies in European Newspaper Culture Sections, 1960-2010 (Routledge, 2018), a book on culture journalism and its transformations in Europe. 